\title{
Persepsi Wisatawan Terhadap Museum Bali Sebagai Daya Tarik Wisata Budaya
}

Ni Luh Yuning Wirayanthi a,1, Ida Ayu Suryasih a, 2

1yuningwirayanthi22@gmail.com, 2idaayusuryasih@unud.ac.id

a Program Studi S1 Destinasi Pariwisata, Fakultas Pariwisata,Universitas Udayana, Jl. Dr. R. Goris, Denpasar, Bali 80232 Indonesia

\section{Abstract}

The museum is one of the cultural heritages that should be preserved. Museum Bali is one of the old museum is located in the city of Denpasar and became an icon of cultural tourism. The purpose of this study to determine the perceptions and motivations of tourists to Museum Bali as cultural tourist attractions in Denpasar. This study uses primary data and secondary. Data collection technique used observation, interview, questionnaire, and documentation. Sampling technique using the formula slovin by sampling using accidental sampling devoted to 96 respondents. To analyze data using qualitative descriptive. The results of this study indicate that the perception of tourists to Museum Bali shows a good response because from 17 indicators used as a measure of the response has been positive, there are two indicators got bad response. Advice can be given is the need for more interesting information and support so that tourists are more interested to know the collections of the Museum Bali. There needs to be a cultural attraction, the better promotion and attractive to increase the number of tourist visits.

Keywords: Tourist Perception, Museum, Cultural Tourist Attraction

\section{PENDAHULUAN}

Museum merupakan tempat yang dari abad ke-18 oleh pemikiran renaissance digunakan untuk menyimpan benda-benda kuno dan bersejarah. Hingga saat ini Museum dimanfaatkan untuk menyimpan koleksi budaya, peninggalan sejarah, hasil karya seni, sampai benda pada jaman prasejarah.

Menurut (Benediktason, 2004:8) museum digunakan untuk media pendidikan dan pencerahan untuk umum. Di jaman modern ini selain untuk media pendidikan museum juga dimanfaatkan sebagai kegiatan pariwisata. Di Negara maju kegiatan pariwisata museum sangat diminati wisatawan.

Salah satu museum yang terkenal adalah Museum Louvre yang terletk di Kota Paris. Memiliki 8 juta kunjungan wisatawan di tahun 2014. Di Indonesia sendiri terdapat sekitar 300 museum yang menyimpan benda sejarah dan budaya dari setiap daerah (Kemendiknas)

Di Bali Museum yang sangat terkenal dan mencerminkan budaya dan sejarah adalah Museum Bali. Merupakan Museum tertua dan sangat berkaitan dengan pariwisata budaya karena mengandalkan potensi kebudayaan sebagai daya tarik paling dominan dan menyimpan 9 dari 10 elemen budaya yang menjadi daya tarik wisata (Geriya, 1995:103) yaitu: koleksi berupa kerajinan, tradisi, sejarah dari suatu tempat, arsitektur Bali, kesenian, cara hidup masyarakat, agama, bahasa, dan pakaian tradisional.

Gaya bangunannya merupakan perpaduan antara "pura" yaitu tempat suci agama hindu dan "puri" yaitu tempat tinggal para raja Bali. Museum Bali mulai buka dan dikunjungi wisatawan yaitu pada tahun 1932. Adapun data kunjungan wisatawan ke Museum Bali selama 5 tahun terakhir menunjukkan bahwa pertumbuhan kunjungan wisatawan tidak stabil dari tahun ke tahun. Dari tahun 2011 yang berpenilaian 31.578 wisatawan ke tahun 2012 yang berpenilaian 29.197 wisatawan mengalami penurunan sebesar 7,54 persen. Mengalami penurunan kembali di tahun 2013 yang berpenilaian 26.215 wisatawan sebesar 10,21 persen. Pada tahun 2014 kunjungan wisatawan naik sebesar 64,02 persen menjadi 42.998 dan pada tahun 2015 kembali mengalami penurunan sebesar 12,71 persen menjadi 37.532.

Berdasarkan ketidakstabilan kunjungan wisatawan dan untuk mengetahui bagaimana pendapat wisatawan terhadap Museum Bali perlu adanya penelitian terkait persepsi wisatawan terhadap Museum Bali sebagai daya tarik wisata budaya.

\section{TINJAUAN PUSTAKA}

1. Konsep Museum

Menurut Ardika, 2015:18 museum merupakan tempat untuk memajang atau menyimpan benda warisan budaya, dalam 
fungsinya sebagai pengelola warisan budaya sesungguhnya memiliki ideology yang sama dengan pariwisata budaya. Museum memberikan informasi dan pelayanan kepada publik atau wisatawan tentang fungsi dan makna suatu artefak ataupun kegiatan tertentu.

\section{Daya Tarik Wisata}

Pengertian Daya Tarik Wisata menurut Undang-undang Republik Indonesia No. 10 tahun 2009 tentang Kepariwisataan Bab I, pasal 5 , menyebutkan sebagai berikut "daya tarik wisata" adalah segala sesuatu yang memiliki keunikan, keindahan, dan nilai yang berupa keanekaragaman kekayan alam, budaya dan hasil buatan manusia yang menjadi sasaran atau tujuan kunjungan wisatawan.

\section{Konsep Wisatawan}

Setiap orang yang mengunjungi negara yang bukan merupakan tempat tinggalnya untuk berbagai tujuan, tetapi bukan untuk mencari nafkah atau penghidupan dari negara yang dikunjungi". United Nation Conference on Travel and Tourism (Pitana dan Gayatri, 2005:42).

4. Teori Persepsi

Philip Kotler, 1993 menjelaskan bahwa persepsi adalah proses bagaimana seseorang menyeleksi, mengatur, dan menginterpretasikan masukan-masukan informasi untuk menciptakan gambaran keseluruhan yang berarti. Menurut Gibson (Kusherdyana, 2013:17) persepsi adalah proses kognitif yang dipergunakan oleh individu untuk menafsirkan dan memahami dunia sekitarnya, dengan kata lain bahwa persepsi mencakup penerimaan stimulus, pengorganisasian, dan penerjemahan atau penafsiran stimulus yang diorganisasikan dengan cara yang dapat mempengaruhi perilaku dan pembentukan sikap.

Jadi dapat disimpulkan bahwa persepsi adalah proses seseorang individu untuk menyeleksi, mengorganisasi menyeleksi informasi, dan menafsirkan stimulus yang dapat mempengaruhi pembentukan sikap dan perilaku.

\section{METODE PENELITIAN}

Penelitian ini berlokasi di Museum Bali yang berada di sebelah timur lapangan Puputan Badung. Mempunyai luas 65 Ha membujur dari selatan ke utara, dengan gaya khas bangunan Bali museum ini memiliki empat gedung yang difungsikan sebagai tempat penyimpanan koleksi yaitu: Gedung Timur, Gedung Buleleng, Gedung Karangasem, dan Gedung Tabanan. Persepsi yang dibahas dalam penelitian ini adalah persepsi wisatawan terhadap potensi fisik dan potensi non fisik Museum Bali.

Metode pengumpulan data yang dilakukan adalah dengan observasi, wawancara, kuesioner, dokumentasi dan studi pustaka. Observasi dilakukan untuk mengetahui keadaan langsung di lapangan dan untuk melengkapi hasil temuan dilapangan. Kuesioner digunakan untuk mengetahui persepsi wisatawan terhadap Museum Bali. Wawancara dilakukan dengan wisatawan untuk melengkapi hasil dan untuk menguatkan hasil temuan di lapangan.

Penentuan sampel dihitung dengan rumus Slovin (Noor, 2011:158), dengan populasi sebesar 2.792 dihitung dengan taraf kesalahan $10 \%$, maka sampel yang ditentukan adalah sebanyak 96 responden. Teknik pengambilan sampel menggunakan accidental sampling yaitu siapa saja yang kebetulan bertemu dengan peneliti dan dipandang cocok untuk dijadikan sumber data. Penelitian ini menggunakan analisis deskriptif kualitatif, skala likert digunakan untuk menentukan range nilai persepsi wisatawan dengan lima penilaian kategori.

\section{HASIL DAN PEMBAHASAN}

Persepsi dalam penelitian ini dilihat dari dua aspek yaitu aspek fisik dan non fisik Museum Bali. Terdiri dari 17 variabel dan setelah dianalisis dengan menggunakan skala likert maka hasil yang diperoleh dapat dilihat pada Tabel 4.1

Tabel 4.1

Persepsi Wisatawan Terhadap Museum Bali

\begin{tabular}{c|c|c|c|c|c}
\hline No & SB & B & C & TB & STB \\
\hline 1 & 30 & 38 & 16 & 8 & 4 \\
\hline 2 & 32 & 33 & 24 & 3 & 4 \\
\hline 3 & 5 & 20 & 30 & 29 & 12 \\
\hline 4 & 19 & 55 & 18 & 4 & 0 \\
\hline 5 & 48 & 39 & 9 & 0 & 0 \\
\hline 6 & 33 & 37 & 26 & 0 & 0 \\
\hline 7 & 12 & 22 & 32 & 15 & 15 \\
\hline 8 & 34 & 48 & 14 & 0 & 0 \\
\hline 9 & 21 & 54 & 9 & 12 & 0 \\
\hline 10 & 27 & 33 & 25 & 8 & 3 \\
\hline
\end{tabular}




\begin{tabular}{c|c|c|c|c|c}
11 & 28 & 50 & 18 & 0 & 0 \\
\hline 12 & 52 & 40 & 4 & 0 & 0 \\
\hline 13 & 18 & 16 & 28 & 34 & 0 \\
\hline 14 & 37 & 48 & 11 & 0 & 0 \\
\hline 15 & 33 & 52 & 4 & 4 & 3 \\
\hline 16 & 16 & 18 & 36 & 15 & 11 \\
\hline 17 & 22 & 20 & 24 & 30 & 0 \\
\hline Penilaian & $\begin{array}{c}46 \\
7\end{array}$ & 623 & 328 & 162 & 52 \\
\hline
\end{tabular}

Sumber: Hasil Penelitian, 2016

\section{Keterangan:}

1. Kebersihan, 2. Keamanan, 3. Kebersihan Toilet, 4. Fasilitas Parkir, 5. Keberadaan Konter Tiket, 6. Harga Tiket, 7. Keberadaan Toko Souvenir, 8. Kebersihan Koleksi, 9. Kelengkapan Koleksi, 10. Ketersediaan Informasi pada Koleksi, 11. Penempatan Koleksi, 12. Pelayanan Penjual Tiket, 13. Pelayanan Informasi, 14. Nilai Budaya Koleksi, 15. Nilai Sejarah Koleksi, 16. Keberadaan Tempat Sampah, 17. Atraksi Budaya.

Jika dilihat dari Tabel 4.1 persepsi wisatawan terhadap Museum Bali mendapat tanggapan yang positive. Persepsi wisatawan terhadap kebersihan Museum Bali mendapat tanggapan baik dengan penilaian 38 wisatawan. Sesuai dengan hasil observasi lapangan bahwa Museum Bali selalu terlihat rapih dan bersih, taman selalu tertata rapih. Hal tersebut didukung dengan adanya petugas kebersihan yang selalu berjaga setiap hari. Namun dari hasil wawancara dengan salah satu wisatawan asal jerman yang berpendapat bahwa di dalam gedung penyimpanan koleksi terasa lembab dan terdapat bau yang menyengat.

"I was smell unpleasant in the room, it's very moist, closed, and dark but for all is very nice." (hasil wawancara, 13 juni 2016)

Persepsi wisatawan terhadap keamanan museum mendapat tanggapan baik dengan penilaian 33 wisatawan. Hal tersebut dibuktikan dengan tersedianya petugas keamanan yang berjaga di bagian depan museum dan terdapat beberapa CCTV di areal museum. Namun jika dilihat dari keberadaan penjual cenderamata yang berjualan di area dalam Museum Bali terlihat sedikit mengganggu wisatawan yang ingin menikmati wisata mereka. Perlu disediakan tempat khusus agar wisatawan merasa nyaman.

Persepsi wisatawan terhadap kebersihan toilet mendapat tanggapan cukup dengan penilaian 30 wisatawan. Jika dilihat dari hasil observasi keadaan toilet Museum Bali perlu sedikit adanya perbaikan dan kebersihan yang harus selalu terjaga mengingat toilet adalah hal yang penting untuk ada di sebuah daya tarik wisata.

Persepsi wisatawan terhadap keberadaan parkir di Museum Bali mendapat tanggapan baik dengan penilaian 55 wisatawan. Fasilitas parkir di Museum Bali luas dan tertata rapi, jika dilihat dari hasil observasi parkir tersebut merupakan parkir bersama dengan pengunjung lapangan puputan, namun tidak sulit untuk mencari parkir karena areal yang luas.

Persepsi terhadap Keberadaan Konter Tiket mendapat tanggapan sangat baik dengan penilaian 48 wisatawan. Konter tiket merupakan hal utama yang perlu ada di sebuah daya tarik wisata, karena selain difungsikan untuk menjual tiket konter yang ada di Museum Bali juga berfungsi sebagai pusat untuk mendapat informasi terkait museum.

Persepsi wisatawan terhadap harga tiket masuk Museum Bali mendapat tanggapan baik dengan penilaian 37 wisatawan. Museum Bali merupakan museum yang langka dan satusatunya museum etnografi yang ada di Bali. Namun jika dilihat dari harga tiket museum ini bisa dikatakan murah karena masih bisa terjangkau untuk kalangan menengah ke bawah yaitu sebesar 20 ribu rupiah untuk wisatawan asing, 10 ribu rupiah untuk wisatawan domestik, dan 5 ribu rupiah untuk anak-anak.

Persepsi wisatawan terhadap keberadaan toko souvenir di Museum Bali mendapat tanggapan cukup. Sesuai dengan hasil observasi lapangan terdapat sebuah kantin kecil di belakang konter tiket dan juga menyediakan beberapa souvenir. Namun karena tempatnya yang tidak terlihat, beberapa wisatawan mengatakan tidak tahu terhadap keberadaan toko souvenir tersebut. Adapun hasil wawancara dengan wisatawan asal Belanda yang menyatakan bahwa dia tidak melihat adanya toko souvenir di dalam Museum Bali.

"Saya tidak melihat adanya toko souvenir di dalam museum ini, yang saya lihat 
hanya pedagang yang datang dari luar museum" (6 juni 2016)

Persepsi wisatawan terhadap kebersihan koleksi Museum Bali mendapat tanggapan baik dengan penilaian 48 wisatawan. Koleksi Museum Bali tertata di dalam kotak, kebersihan selalu dijaga, selain itu koleksi juga diberikan perawatan secara berkala dengan obat-obatan tradisional seperti sereh agar awet dan terhindar dari bakteri dan jamur.

$$
\text { Persepsi wisatawan terhadap }
$$

kelengkapan koleksi Museum bali mendapat tanggapan baik dengan penilaian 54 wisatawan. Dilihat dari hasil observasi di lapangan bahwa penilaian koleksi Museum Bali sangat lengkap dan beragam, begitu juga pendapat salah satu wisatawan asing asal swedia yang merasa kagum akan koleksi-koleksi budaya yang terdapat di Museum Bali.

"I first heard the name of the museum bali, I do not know, my travel guide that introduces this place and I was very excited with the collections that are here."(5 juli 2016)

Persepsi wisatawan terhadap ketersediaan informasi pada benda koleksi museum mendapat tanggapan baik dengan penilaian 33 wisatawan. Hal ini didukung dengan adanya 2 informasi dalam 2 bahasa yaitu bahasa Indonesia, dan bahasa inggris, selain itu di depan gedung karangasem juga terdapat sebuah video yang berisi tentang informasi mengenai Museum Bali. Namun demikian untuk membuat perjalanan wisatawan berkesan perlu adanya penambahan informasi yang menarik seperti video pada setiap benda koleksi museum yang dianggap perlu untuk wisatawan ketahui lebih dalam, sehingga wisatawan akan semakin tertarik untuk tahu. Adapun pendapat salah satu wisatawan asal jerman terhadap ketersediaan informasi yaitu:

"it's interesting, out their should be more explanation in english, not only one sentence."(23 juni 2016)

Persepsi wisatawan terhadap penempatan koleksi Museum Bali mendapat tanggapan baik dengan penilaian 50 wisatawan.
Dilihat dari hasil observasi penempatan koleksi tertata rapi dan bersih di dalam masing-masing kotak.

Persepsi wisatawan terhadap pelayanan penjual tiket di Museum Bali mendapat tanggapan sangat baik dengan penilaian 52 wisatawan. Jika dilihat dari observasi lapangan pelayanan penjualan tiket dijaga langsung oleh staff UPTD Museum Bali. Pelayanan tiket sangat ramah dan juga cepat. Hal ini juga dibuktikan dengan tanggapan salah satu wisatawan asal prancis.

"I really appreciate the service ticket, they are very friendly and full of smiles. but I deplore the absence of a competent guide for telling me about the information I needed".(21 juli 2016)

Persepsi wisatawan terhadap pelayanan informasi di Museum Bali mendapat tanggapan tidak baik. Wisatawan yang datang secara individu memerlukan bantuan pemandu wisata yang dapat menjelaskan secara rinci terkait koleksi yang ada. Informasi yang minim di setiap koleksi membuat wisatawan kurang mengerti tentang arti dan cerita dari setiap koleksi. Namun dari hasil observasi lapangan beberapa penjual cenderamata yang ada di museum beberapa kali membantu wisatawan lokal dalam memberi informasi tambahan. Namun hal tersebut hanya terbatas untuk wisatawan lokal karena kurangnya keahlian dalam berbahasa inggris.

Persepsi wisatawan terhadap nilai budaya Museum Bali mendapat tanggapan baik dengan penilaian 48 wisatawan yang menjawab baik. Bali memiliki beragam budaya dan sejarah masa lalu dan perlu waktu lama untuk mempelajari semua itu, namun dengan keberadaan Museun Bali dengan koleksi budaya, jaman pra sejarah, dan sejarah Bali membuat wisatawan lebih mudah tahu secara singkat mengenai Bali. Salah satu pendapat wisatawan prancis terhadap nilai budaya museum yaitu:

"bali museum has a large collection of the culture, and this needs to be maintained and cared for, so they will still be here in a long time."(4 juni 2016) 
Persepsi wisatawan terhadap nilai sejarah museum mendapat tanggapan baik dengan penilaian 55 wisatawan. Hal tersebut dibuktikan dengan ketertarikan wisatawan dalam mengetahui benda-benda sejarah Bali yang tertata rapi di dalam gedung timur areal Museum Bali. Berbagai peninggalan pada jaman perjuangan masih tersimpan dengan baik.

Persepsi wisatawan terhadap keberadaan tempat sampah mendapat tanggapan cukup dengan penilaian 36 wisatawan. Dilihat dari hasil observasi keberadaan tempat sampah masih minim.

Persepsi wisatawan terhadap atraksi budaya di Museum Bali mendapat tanggapan kurang baik dari wisatawan dengan penilaian 30 wisatawan yang memilih tidak baik. Jika dilihat dari hasil observasi di lapangan belum ada atraksi budaya yang dapat disaksikan oleh wisatawan selama berada di areal museum. Atraksi seperti gambelan bali, ataupun tarian yang dapat menghibur wisatawan yang berkunjung. Hal tersebut juga bisa menjadi kegiatan untuk melestarikan budaya Bali agar tidak tergerus oleh jaman globalisasi.

\section{SIMPULAN DAN SARAN}

\section{Simpulan}

Dari keseluruhan pendapat wisatawan terhadap potensi fisik dan potensi non fisik Museum Bali dapat disimpulkan mendapat tanggapan yang positive. Hal tersebut terbukti dari 17 variabel yang diukur dua variabel mendapat tanggapan sangat baik. sepuluh variabel mendapat tanggapan baik, tiga variabel dinyatakan cukup, dan dua variabel dinyatakan tidak baik.

Adapun variabel yang mendapat tanggapan cukup yaitu kebersihan toilet, keberadaan toko souvenir, dan keberadaan tempat sampah perlu ditelaah dengan baik agar wisatawan merasa berkesan saat berada di Museum Bali. Dua variabel yang mendapat tanggapan tidak baik adalah pelayanan informasi karena kurangnya pemandu wisata yang membantu wisatawan dalam memahami makna dan cerita dari setiap koleksi museum, hal ini juga berhubungan dengan informasi tertulis yang ada di setiap koleksi yang masih sangat minim untuk memberi informasi lebih dalam ke wisatawan. Persepsi terhadap atraksi wisata budaya juga mendapat tanggapan kurang baik dari wisatawan.

\section{Saran}

Berkaitan dengan beberapa persepsi wisatawan yang masih mendapat tanggapan kurang baik maka perlu adanya pembenahan sistem agar wisatawan merasa nyaman dan berkesan saat berada di areal Museum Bali. Koleksi museum yang sarat dengan makna dan cerita tentang kehidupan Bali sangat menarik bagi wisatawan namun bagaimana cara untuk mengkemas produk wisata ini agar wisatawan memahami informasi tentang koleksi yang ada di museum.

Untuk pihak pengelola sendiri perlu adanya penambahan informasi pada setiap koleksi museum, seperti penambahan video yang dapat ditonton oleh wisatawan agar mereka memiliki gambaran tentang koleksi tersebut. Selain video juga perlu adanya pemandu wisata untuk wisatawan yang datang sendiri.

Sebagai daya tarik wisata budaya pihak museum juga perlu menambah atraksi budaya seperti gambelan dan tarian, selain bisa menghibur di sela waktu wisatawan berkeliling hal tersebut juga dapat melestarikan kesenian Bali.

\section{Daftar Pustaka:}

Undang-Undang Rebuplik Indonesia No. 10 Tahun 2009 Tentang Kepariwisataan

Ardika, I Wayan. 2015. Warisan Budaya Perspektif Masa Kini. Denpasar: Universitas Udayana.

Benediktason, Gudbrandur. 2004. Museum and Tourism. Stakeholder,Resource and Sustainable Development. Master's Dissertation. Musion. Goteberg University.

Geriya, Wayan. 1995 . Pariwisata dan Dinamika Kebudayaan Lokal, Nasional, Global. Denpasar : Upada Sastra.

Kotler, Philip. 1995. Marketing Manajement Analisys, Planning, Implementation \& Control. Prentice Hall Int.

Kusherdyana. 2013. Pemahaman Lintas Budaya. Bandung: Alfabeta

Noor, Juliansyah. 2011. Metodologi Penelitian. Jakarta: KENCANA.

Pitana, I Gede, Putu G Gayatri. 2005. Sosiologi Pariwisata. Yogyakarta: Andi Offset

Dinas Provinsi Bali. 2015. Data statistik Provinsi Bali tahun 2015. Denpasar: Pemerintah Provinsi Bali. 